\title{
Representación de la Historia en la Literatura: La Lengua de la Ciudad Condal Como Urbe Novelística*
}

\section{Representation of History in Literature: The Language of Barcelona as a Novel City}

\author{
Zeynep ÖNAL ${ }^{1}$ [D
}

*Bu çalıșma 18-20 Eylül 2019 tarihlerinde İstanbul Üniversitesi Edebiyat Fakültesi'nde düzenlenen "Şehrin Dili" konulu II. Uluslararası Sosyal Bilimler Kongresi'nde Türkçe sunulan bildirinin genişletilerek makale haline getirilmiş ve İspanyolca yazılmış versiyonudur.

${ }^{1}$ Assoc. Prof., Istanbul University, Faculty of Letters, Department of Western Languages and Literatures, Spanish Language and Literature, Istanbul, Turkey

ORCID: Z.Ö. 0000-0002-7758-7204

Corresponding author:

Zeynep ÖNAL,

İstanbul Üniversitesi, Edebiyat Fakültesi, Batı Dilleri ve Edebiyatları Bölümü, İspanyol Dili ve Edebiyatı Anabilim Dalı, İstanbul, Türkiye

E-mail: ezeyneponal@gmail.com

Submitted: 29.01 .2020

Accepted: 10.03 .2020

Citation: Onal, Z. (2020). Representación de la historia en la literatura: La lengua de la ciudad condal como urbe Novelística. Litera, 30(1), 121-136.

https://doi.org/10.26650/LITERA2020-0011

\section{RESUMEN}

Este trabajo tiene el objetivo de estudiar dos destacadas novelas de la literatura española del siglo XX, La ciudad de los prodigios de Eduardo Mendoza y Nada de Carmen Laforet, con la intención de exponer el fuerte contraste en la narración de dos Barcelonas, telón de fondo de ambas novelas: la del período de transición del siglo XIX al XX y la del período de posguerra del siglo XX. Los dos relatos exponen, como trasfondo de las historias contadas, la Barcelona de la época, ambas completamente distintas tanto en términos de desarrollo como de estancamiento en la vida social y urbana. La ciudad de los prodigios relata el brillante ascenso de la ciudad en los niveles social, industrial y económico durante el paso del siglo XIX al siglo XX. La ciudad, narrada entre las dos Exposiciones Universales - 1888 y 1929 - presenta un escenario de desarrollos significativos en materia de crecimiento social, modernización cívica y bienestar material. En la era de grandes invenciones, la lengua de la ciudad refleja la transformación, el progreso y la esperanza. Nada de Carmen Laforet relata la Barcelona de la posguerra. El relato empieza en 1939, al terminar la Guerra Civil Española, y concluye cerca de un año más tarde. La ciudad presenta una imagen abatida y triste, como consecuencia del ambiente imperante de amargura y desconsuelo. La lengua de la ciudad se constituye ora por un profundo silencio ora por la violencia verbal, consecuencia natural de la tensión que reina en la ciudad.

Palabras clave: Eduardo Mendoza, La ciudad de los prodigios, Carmen Laforet, Nada, Barcelona

\section{ABSTRACT}

This study aims to analyse two of the most influential novels of $20^{\text {th }}$ century Spanish literature, The city of marvels by Eduardo Mendoza and Nada by Carmen Laforet in order to reveal the strong contrast between these two Barcelonas, the background of which, are as follows - the Barcelona of the transition period between the $19^{\text {th }}$ and $20^{\text {th }}$ centuries and the post-Civil War Barcelona of the $20^{\text {th }}$ century. Both novels use Barcelona as a setting for their stories and these two Barcelonas are completely different from each other in terms of both progress in and suspension of social and city lives. The city of marvels tells the outstanding rise of Barcelona in social, 
industrial and economic levels during the period between the end of the $19^{\text {th }}$ century and the beginning of the $20^{\text {th }}$ century. The tale of the city is told between Barcelona's World Fairs of 1888 and 1929; during this time the city presents a significant development with respect to social growth, modernization and well-being. In the age of great inventions, the language of the city reflects trasformation, progress and hope. Carmen Laforet's Nada tells of a post-Civil War Barcelona. The story begins in 1939, at the end of the Spanish Civil War, and ends almost a year later. The city presents a sad and miserable image as a result of the prevailing atmosphere of grief and disconsolation. The language of the city is constructed at times by a profound silence and at others a verbal violence, as a natural consequence of the tension that reigns

Keywords: Eduardo Mendoza, The city of marvels, Carmen Laforet, Nada, Barcelona

\section{EXTENDED ABSTRACT}

The city of marvels is about the rise of a young and poor immigrant, who leaves his home in the countryside of Catalonia and moves to the big city with great expectations of creating a new life. The year when Onofre Bouvila arrives in Barcelona, the city is in a stage of industrial and economic growth; as a result of the ongoing transformation the city has a lively and turbulent social life. The working class, anarchists, trade unionists, aristocrats, members of the middle class, peasants, clergymen, police forces, leaders of politics, businessmen, capitalists, men of law, leaders of the world of crime, and members of the criminal underworld are the social classes of the time; in the diversity of the social groups that comprise the people of Barcelona, the language of the city reflects hope of growth and renovation. The story of Onofre Bouvila starts in 1887, the year he goes to Barcelona hoping to have a better life, and ends in 1929, the year he leaves the city forever. The fiction is interwoven with a historical background: the historical frame of the story comprehends the time that passes from 1888 to 1929, the period between two World Fairs in Barcelona. The stories of the fictional character and of Barcelona are told in parallel; while Onofre Bouvila rises to climb and reach the summit of the criminal and financial world of Barcelona, the city grows without interruption. In the age of great inventions and complete belief in science, the city is the scene of two World Fairs, working class revolts, mafia wars, swindling in the real estate sector, social, economic and political convulsions, the First World War, the beginning of the age of cinema, the dreadful time of Primo de Rivera, and the evolution of aeronautics. In the rich variety of characters and events, the city creates its own language.

Nada tells the story of an orphaned young girl who walks away from her small town and moves to Barcelona to build a new life and to attend university. In a devastated post-war Barcelona, Andrea begins to live with her mother's family, which consists of her aunt, uncles and grandmother. The story of Andrea begins in 1939, shortly after 
the war ends, and lasts for almost a year. The Barcelona of the post-war period looks completely different from the lively, dynamic city in The city of marvels: the streets are desolate and lifeless. The young girl quickly understands the poor, filthy, and miserable atmosphere of her home filled with hate and violence. Andrea faces the hypocrite, conservative middle-class society of Barcelona. While she feels threatened by the language of the family members that reflects rage and cruelty, she finds herself embraced by the compassionate, warm language of her friends in the university. At the beginning of the forties, the language of the city reflects the tension of the streets, the suffocating atmosphere, the silence of its inhabitants, the grief and the depression.

Barcelona forms the background in both novels and the stories of the characters are set in the core of the city. The city of marvels tells a time of the city in constant evolution. Nada tells a very painful period in the history of Spain. The history of Onofre Bouvila ends in 1929 and the story of Andrea starts in 1939. Only ten years after, the difference is huge between the two Barcelonas: it is no longer possible to talk about evolution since in the course of only ten years, the city has become a ghost.

The present work intends to demonstrate, via fictional characters that serve as witnesses of their time, the sharp difference between the two Barcelonas - a city of great changes and a city from an age of fear and secrecy. 


\section{Introducción}

La ciudad de los prodigios cuenta el impresionante ascenso de un joven inmigrante misérrimo del sudoeste de la Cataluña agraria a la cumbre del mundo delictivo y financiero de Barcelona, colocando la ciudad como telón de fondo de la historia. La Barcelona de fines del siglo XIX presenta una vida social animada, bulliciosa y tumultuosa; la ciudad está pasando por una transformación industrial y una etapa de ascenso económico. En 1888, el año de inauguración de la primera Exposición Universal de Barcelona, las capas sociales se componen de obreros que trabajan en las construcciones de la Exposición Universal - peones, jornaleros, patronos, capataces, maestros de obras, albañiles, arquitectos-, obreros portuarios, charlatanes, curanderos, herbolarios, anarquistas, sindicalistas, aristócratas, burgueses, clérigos, policía, prohombres de la vida política y mercantil, empresarios, capitalistas, agentes de la ley, delincuentes, gente de bien, viciosos, jefes del mundo delictivo, el hampa, gente marginal de los barrios de mala fama. La lengua de la ciudad narrada durante este lapso que transcurre entre las dos Exposiciones Universales de 1888 y 1929 está formada por las capas sociales que favorecen el progreso económico y el desarrollo social. En la era de grandes invenciones, la ciudad refleja esperanzas de crecimiento y renovación.

La novela ofrece una trama en la que la ficción y la historia se entretejen hasta formar una estructura narrativa: la parte ficticia de la narración relata las peripecias del protagonista desde 1887, año de su llegada a Barcelona, hasta 1929, el año en que desapareció de ella; el marco histórico entrelazado con ficción comprende el tiempo desde 1888 hasta 1929, transcurso entre las dos Exposiciones Universales. La ciudad de los prodigios, en la que las historias del escalamiento del protagonista y la progresión de la ciudad se construyen en paralelo, "se alza [...] como un excepcional mosaico narrativo absolutamente idóneo para estudiar [...] el funcionamiento del espacio" (Valles Calatrava, 2017, p. 192). Sin embargo, el marco histórico del relato no se limita al intervalo entre las dos exposiciones sino que se extiende a un período histórico mucho más amplio, aportando datos acerca de los orígenes y la evolución de la ciudad y los períodos por los que pasa a lo largo de su trayectoria histórica. Los acontecimientos históricos tampoco se limitan a la ciudad, sino que se introduce una diversidad histórica, tanto geográfica como temporal, que va más allá de la historia de Barcelona. Margarita Garbisu Buesa (2000) sostiene que "Mendoza consigue confundir al lector jugando con estos acontecimientos y personajes de la historia al introducirlos entre los acontecimientos 
y personajes de la ficción". Para Garbisu Buesa, se trata de un juego entre la realidad y la ficción: "Juega - realmente juega - con datos reales (históricos al menos en apariencia) y los enlaza perfectamente con secuencias ficticias" (p. 16). Las secuencias temporales no siguen un orden cronológico y se observa el frecuente uso de las anacronías en el relato; como consecuencia se consigue una estructura narrativa con varios niveles narrativos. La diversidad de los personajes y los acontecimientos ficticios e históricos enriquece el discurso narrativo y la ciudad construye su propia lengua, convirtiéndose en protagonista del relato.

Nada cuenta la llegada de una joven de pueblo a la gran ciudad, al finalizar la Guerra Civil Española, con ilusiones de estudiar en la universidad y empezar una nueva vida. En la Barcelona de posguerra, el lector se convierte en testigo del cese de la vida social en múltiples niveles y de la pobreza, la miseria, el hambre, el ambiente de odio y violencia. La entusiasta e inocente Andrea pronto se enfrenta con la sociedad burguesa conservadora e hipócrita de la Barcelona de posguerra. La lengua de odio y violencia en la casa de sus parientes se contrapone a la lengua comprensiva, compasiva y alentadora del ambiente universitario, mientras que la lengua de la ciudad en la Barcelona de la década de los cuarenta refleja la tensión de la calle, la atmósfera asfixiante, la mudez de sus habitantes, la pesadumbre y el abatimiento.

La novela narra un período histórico doloroso en la historia de España. La historia de la protagonista empieza en 1939, justo después de terminar la Guerra Civil Española y se prolonga casi un año. Barcelona presenta una imagen abatida y triste bajo el gobierno de Franco. La pérdida total de la esperanza, la ira, la angustia provocadas por el ambiente asfixiante de la vida cotidiana se ven reflejadas en la lengua y la conducta agresivas de los miembros de la familia de Andrea. La vida miserable de una familia burguesa en decadencia que ha dejado atrás los buenos tiempos revela las consecuencias destructivas de la guerra. El relato se cuenta a través del contraste entre los espacios interior y exterior. El lector observa la tensión del ambiente tanto en la casa como en la calle. Las secuencias temporales siguen un orden cronológico con referencias al pasado de los personajes. La realidad histórica cobra vida en ficción; la ciudad compone su peculiar lenguaje mudo al fondo de la historia y a la vez expone los efectos catastróficos de la Guerra por medio de los personajes de la narración. 


\section{La lengua de la ciudad}

"El año en que Onofre Bouvila llegó a Barcelona la ciudad estaba en plena fiebre de renovación” (Mendoza, 2018, p. 15). “Por dificultades en el último momento para adquirir billetes, llegué a Barcelona a medianoche, en un tren distinto del que había anunciado, y no me esperaba nadie" (Laforet, 2018, p. 71). La ciudad de los prodigios de Eduardo Mendoza y Nada de Carmen Laforet, consideradas por los críticos de la literatura entre las novelas más importantes de la literatura española del siglo XX, empiezan con estas afirmaciones.

La frase que abre el relato de La ciudad de los prodigios indica la evolución de una ciudad que "no cesaba de crecer" (Mendoza, 2018, p. 20) durante el período del paso del siglo XIX al XX. Es la era de los inventos, el progreso y la modernización. Para Mendoza "dejar de evolucionar, o peor aún marchar hacia atrás, es siempre mortal" (Hoeg, 2007, p. 861). María José Giménez Mico (2000) sostiene que "en esta novela se le presenta al lector una Barcelona nueva que surge de las necesidades e inconvenientes urbanísticos" (p. 18), estimulados por las exposiciones de 1888 y 1929. En el transcurso de cuatro décadas, será particularmente la clase obrera la que hará posible el desarrollo:

La industrialización forzosa y acelerada provocada por la primera guerra mundial, la necesaria mano de obra campesina atraída a la ciudad para alimentar las industrias nacientes y el consiguiente desarraigo de estos excampesinos, producto del éxodo rural, es puesto de manifiesto en $L a$ ciudad de los prodigios a través de la masa de obreros anónimos que van construyendo la ciudad de Barcelona a lo largo de la novela. (Giménez Micó, 2000, p. 190)

Barcelona se describe como la parte de "la Cataluña próspera, clara, jovial y algo cursi que baña el mar" (Mendoza, 2018, pp. 20-21). Aun si la ciudad pasa por momentos difíciles en el período que transcurre entre las dos exposiciones, la lengua de la ciudad está llena de vida y la ciudad presenta una imagen enérgica en todo momento.

La Barcelona descrita en Nada no tiene ningún parecido con la creciente ciudad dinámica de La ciudad de los prodigios: En la Barcelona de La ciudad de los prodigios la ascendente clase burguesa es señal de progreso; en Nada, Barcelona es una ciudad donde el curso de la evolución se ve interrumpido de manera abrupta por la guerra y la clase burguesa está en decadencia. Los miembros de la burguesía sienten intensamente 
los efectos del estancamiento; la tía Angustias le describe a Andrea la ciudad con estas palabras: "La ciudad, hija mía, es un infierno. Y en toda España no hay una ciudad que se parezca más al infierno que Barcelona..." (Laforet, 2018, p. 82). Las palabras que se usan para describir la calle son signos de muerte, dolor y amargura; el lector apenas observa actividad humana en la calle:"Había una soledad impresionante, como si todos los habitantes de la ciudad hubiesen muerto" (pp. 154-155). "Los árboles de la calle de Aribau [...] olían a podrido, a cementerio de plantas" (p. 183). "Aquel cielo tormentoso me entraba en los pulmones y me cegaba de tristeza" (p. 274).

Andrea, la joven protagonista de Nada, marcha a Barcelona con grandes esperanzas a la edad de 18 años, y apenas llega, se llena de desilusión al ver la ciudad que había visitado cuando todavía era niña. Esta Barcelona a principios de la década de los cuarenta del siglo XX se ve en pleno contraste con la Barcelona de la última década del siglo XIX. La ciudad está pasando por un ciclo de recesión económica el año en que llega Onofre Bouvila, el joven protagonista de La ciudad de los prodigios, a la edad de 12 años, lleno de ilusiones de empezar una nueva vida en Barcelona, dejando atrás su vida en la Cataluña campesina. Sin embargo "en Barcelona sobran las oportunidades para quien tiene imaginación y ganas de aprovecharlas" (Mendoza, 2018, p. 27) y "la época estaba dominada por la fe en las ciencias" (p. 165). El estúpido dueño de la miserable pensión en la que se hospeda el pobre Bouvila, con solo unos céntimos en el bolsillo, parece ser optimista pese al ambiente pesimista que reina en la ciudad, como lo demuestra cuando subraya la importancia de la época y sus diferencias respecto a las anteriores con el fin de animar a Bouvila: "Piense, joven, que no ha habido en la historia de la humanidad época como ésta: la electricidad, la telefonía, el submarino..., ¿hace falta que siga enumerando portentos? Sólo Dios sabe a dónde vamos a parar" (p. 27).

La Barcelona de 1887, el año en que llega Onofre Bouvila, la ciudad no sólo está pasando por un período de recesión económica, sino que también se muestra como un ser enfermizo, debilitado por el esfuerzo de su transformación:

El esfuerzo exigido por este desarrollo había sido inmenso. Ahora Barcelona, como la hembra de una especie rara que acaba de parir una camada numerosa, yacía exangüe y desventrada; de las grietas manaban flujos pestilentes, efluvios apestosos hacían irrespirable el aire en las calles y las viviendas. Entre la población reinaban el cansancio y el pesimismo. (Mendoza, 2018, p. 27) 
A pesar de la triste descripción de la ciudad al comienzo del relato, a continuación se nos muestra la imagen de una ciudad en desarrollo, llena de vida, pese a todas las vicisitudes ocurridas entre 1887 y 1929: dos exposiciones universales, crecimiento urbano, invenciones, movimientos obreros, guerras mafiosas, estafas en el mercado de inmuebles, agitaciones sociales, económicas y políticas al pasar del siglo XIX al XX, la Primera Guerra Mundial, el comienzo del cine, el aterrador período de Primo de Rivera, la evolución de la aeronáutica.

A lo largo de la historia ficticia de Onofre Bouvila, Barcelona se construye como una ciudad en constante evolución económica e industrial durante el proceso de modernización. En 1929, al mirar por última vez la ciudad y a los visitantes de la segunda Exposición Universal desde la máquina voladora que se ha hecho fabricar con el fin de desaparecer definitivamente, Onofre Bouvila recuerda el año de su llegada a Barcelona:

Ahora veían a sus pies la ciudad entera, [...]. Ay, Barcelona, [...], ¡qué bonita es! ¡Y pensar que cuando yo la vi por primera vez de todo esto que vemos ahora no había casi nada! Ahí mismo empezaba el campo, las casas eran enanas y estos barrios populosos eran pueblos, [...], por el Ensanche pastaban las vacas. (Mendoza, 2018, p. 537)

En la primera noche en la casa de sus parientes, Andrea recuerda la Barcelona de su infancia, cuando la vio un verano por última vez, a sus siete años:

Inmediatamente tuve una percepción nebulosa, pero tan vívida y fresca [...], de lo que era Barcelona en mi recuerdo: [...] Barcelona era también unas aceras anchas húmedas de riego y mucha gente bebiendo refrescos en un café... Todo lo demás, las grandes tiendas iluminadas, los autos, el bullicio, [...] (Laforet, 2018, p. 78).

La ciudad en los recuerdos de Andrea es la Barcelona de 1929, el año en que Onofre Bouvila se marcha de ella. Andrea opina lo siguiente acerca de los tiempos de la juventud de sus abuelos, cuando ve en la casa un cuadro que los retrata en la Barcelona de cincuenta años atrás, a principios de 1890: "Había una larga y difícil historia de sus amores - no recordaba ya bien qué... quizá algo relacionado con la pérdida de una fortuna -. Pero en aquel tiempo el mundo era optimista y ellos se querían mucho" (p. 
79). Estos tiempos optimistas de los que habla Andrea coinciden con el ambiente alegre de Barcelona en 1888, cuando la inauguración de la primera Exposición Universal: "Barcelona entera estaba en fiestas" (Mendoza, 2018, p. 174). También coinciden con la descripción que hace Onofre Bouvila de la ciudad, al recordar las noches de verano del mismo año. Bouvila describe la ciudad a través de las voces joviales que llenan las noches:

En las noches de verano, cuando salía al balcón azuzado por la desazón, percibía los ruidos familiares que llegaban de la calle: entrechocar de platos y soperas, tintinear de vasos, risas, voces y altercados, trinos de jilgueros y canarios enjaulados, un piano en la lejanía, los gorgoritos de una aprendiza de canto, algún perro persistente, la perorata de los beodos asidos a las farolas, los lamentos de los mendigos ciegos que pedían una limosnita por el amor de Dios. Podría pasar en este balcón la noche entera, [...]; pasarme aquí el verano entero, arrullado por los sonidos de esta ciudad anónima. (Mendoza, 2018, p. 184)

La narración en Nada comienza con la llegada de Andrea a la estación de trenes de Barcelona a medianoche; así empieza la historia de la protagonista en una ciudad de posguerra, donde nos encontramos con miseria, hambre, silencio, gritos, tensión y odio. La sensación de libertad que siente Andrea al llegar a la estación, una joven sola en la soledad de la noche, constituye un fuerte contraste con el sentimiento de asfixia que la chica experimenta a lo largo de la narración. Según John W. Kronik (1981), la palabra "asfixia" se repite tantas veces que se convierte en el motivo recurrente del relato: "A pesar de la expectación y alegría que manifiesta la joven al llegar a la ciudad que había soñado, la narradora anuncia la asfixia que va a sufrir Andrea cuando hace que el acto de respirar se transforme lingüísticamente en tarea laboriosa" (p. 196). La trampa creada por la lengua violenta, verbal y físicamente, que define la vida en constante lucha de los miembros de la familia, así como la opresión que ejerce la tía sobre Andrea, se cierran sobre la muchacha, apresándola en el interior de un mundo de temor y angustia. A partir del momento de su llegada a la casa, todo es un tormento para ella: "Luego me pareció todo una pesadilla" (Laforet, 2018, p. 73).

La detallada descripción del ambiente asfixiante, espeluznante y triste de la casa que se hace al inicio del relato, antes de hablar de la ciudad, prepara al lector para lo que va a ver a continuación, en la calle: 
En toda aquella escena había algo angustioso, y en el piso un calor sofocante como si el aire estuviera estancado y podrido. Al levantar los ojos vi que habían aparecido varias mujeres fantasmales. Casi sentí erizarse mi piel al vislumbrar a una de ellas, [...] todas aquellas figuras me parecían igualmente alargadas y sombrías. Alargadas, quietas y tristes, como luces de un velatorio de pueblo. (Laforet, 2018, p. 74)

El horror que se señala en la apariencia de las mujeres se repite cuando Andrea entra en el baño; las palabras que Andrea usa para definir el baño, un espacio que le infunde terror, parecen mostrar que este cuarto tiene vida propia: "Parecía una casa de brujas aquel cuarto de baño, las paredes tiznadas conservaban la huella de manos ganchudas, de gritos de desesperanza. Por todas partes los desconchados abrían sus bocas desdentadas rezumantes de humedad. [...] La locura sonreía en los grifos torcidos" (p. 76). Según Salvador Crespo Matellán (1988), "las descripciones, en el primer capítulo, del recibidor, el cuarto de baño y el salón de la casa a la que llega la protagonista, Andrea, sugieren ya algunos rasgos característicos del conjunto de los personajes que la habitan: sordidez, miseria, abandono, desorden" (p. 139). La casa es como una mezcla de esos personajes estrafalarios con objetos y espacios escalofriantes. Las impresiones que tiene Andrea de la casa evocan la muerte: "Sentí que me ahogaba [...] en este ambiente de gentes y de muebles endiablados. Tenía miedo de meterme en aquella cama parecida a un ataúd" (Laforet, 2018, p. 77). Y al hablar de los abuelos, Andrea opina lo siguiente:"Me complací en pensar en que los dos estaban muertos hacía años. Me complací en pensar que nada tenía que ver la joven del velo de tul con la pequeña momia irreconocible que me había abierto la puerta" (p. 80).

Cuando Andrea se escapa a la calle del asfixiante ámbito de la casa, se siente relativamente libre. Las consecuencias de los efectos destructivos de la guerra se revelan en el lenguaje verbal y corporal de la familia; Andrea se refugia en la limitada libertad de la calle con el fin de huir del ambiente feroz que reina en la casa. El lector conoce la Barcelona del momento a través de los nombres de las calles y los barrios y también por la impresión que deja la ciudad en la protagonista: Las descripciones que Andrea hace tienen la función de transmitir al lector la impresión que le dejan la calle, la luz, la sombra, los colores, los estilos arquitectónicos, la actividad humana o la desolación.

La Barcelona de La ciudad de los prodigios es un escenario en el que el lector contempla una acción ininterrumpida y las vicisitudes del día. En Nada, la ciudad parece un ser 
sin voz ni energías. Cuando Andrea declara que no pasa nada importante en su vida, está enfatizando la inercia de la calle: "iCuántos días sin importancia! Los días sin importancia que habían transcurrido desde mi llegada me pesaban encima, [...] ¡Cuántos días inútiles! Días Ilenos de historias, demasiadas historias turbias. [...] Historias demasiado oscuras para mí" (p. 97). La tensión de una ciudad callada, paralizada en el tiempo, en la que no hay ningún cambio ni progreso, se descarga por medio de los miembros de la casa de la calle de Aribau. El silencio deliberado y la voz perdida por obligación de la ciudad se convierten en un discurso de odio en el espacio cerrado. Los sentimientos y los pensamientos de los miembros de la familia, condicionados por la ira y la desesperación, se estimulan mutuamente y aumentan con palabras que causan mayor ira y desesperación. Cada vez que alguien se dirige a otro, la palabra se convierte en un contenedor de rencor y odio. Román, el tío de Andrea, le explica a la muchacha el motivo: "Parece que el aire está lleno siempre de gritos... y eso es culpa de las cosas, que están asfixiadas, doloridas, cargadas de tristeza. Por lo demás, no te forjes novelas: ni nuestras discusiones ni nuestros gritos tiene causa, ni conducen a un fin..." (p. 93). Miguel Delibes (1990) sostiene que los habitantes de la calle de Aribau son seres atormentados, desquiciados por la guerra (p. 213).

Esta ira violenta y el deseo de venganza son consecuencias de un estado del que no pueden huir ni pueden salvarse: El tío Juan no puede huir de la rabia que tiene hacia todos; Gloria, la mujer de Juan, no puede huir de la ferocidad verbal y física de su marido; el tío Román no puede huir del malvado que hay en su interior. La tía Angustias sí huye de la casa, pero no puede huir de la mujer perversa dentro de sí. La abuela huye de todo: se tapa los ojos y los oídos a las verdades del pasado y el presente; no ve ni oye, ve lo que quiere ver, oye lo que quiere oír y así crea su mundo peculiar, transformando la verdad. Andrea se queda en medio del odio y la implacable violencia crecientes de esta gente. Sin embargo, "a pesar de asistir a las escenas más violentas y crudas, llora pocas veces a lo largo de la novela" (Martín Gaite, 1993, p. 108). Andrea llega a Barcelona como una joven inocente que no conoce el odio: "Andrea no se reconoce en el odio ni comulga con el odio, no acepta ni asume como propia esa herencia obscena y delirante" (Cerezales, 1995). Sin embargo, aprende, en el transcurso del tiempo, a usar palabras afiladas y fuertes contra los habitantes del piso de la calle de Aribau.

El temor infundido en la ciudad después de terminar la guerra se le insinúa al lector con los sucesos ocurridos en la casa de la calle de Aribau: "Por aquellos días vinieron a buscar a Román y se lo llevaron a una checa, querían que hablara y por eso no le 
fusilaron" (Laforet, 2018, p. 104); "Cuando vino un miliciano a registrar la casa yo le enseñé todos mis santos, tranquilamente. 'Pero ¿usted cree en esas paparruchas de Dios?', me dijo. 'Claro que sí, ¿usted no?', le contesté" (pp. 104-105). El silencio en la vida de la ciudad, enfatizado en la novela, indica la tensión de la posguerra: "Era un restaurante curioso. Oscuro, con unas mesas tristes. [...] La gente comía de prisa, mirándose unos a otros, y no hablaban ni una palabra" (p. 163). El temor y la tensión que imperan en la ciudad se sugieren, a lo largo de la narración, de manera implícita; Andrea tanto hace referencias ambiguas a la palabra "guerra", como la subraya de manera explícita:

Fuimos hacia Miramar y nos acodamos en la terraza del Restaurante para ver el Mediterráneo, [...] En las dársenas salían a la superficie los esqueletos oxidados de los buques hundidos en la guerra. A nuestra derecha yo adivinaba los cipreses del Cementerio del Sudoeste y casi el olor de melancolía frente al horizonte abierto del mar. (Laforet, 2018, p. 178)

Según Miguel Delibes (1990) "la guerra es una palabra constante en el libro" (p. 214). En Nada, el mar es símbolo de sufrimiento y muerte; en La ciudad de los prodigios, acentúa la vida:

Aunque a finales del siglo XIX ya era un lugar común decir que Barcelona vivía "de espaldas al mar", la realidad cotidiana no corroboraba esta afirmación. Barcelona había sido siempre y era entonces aún una ciudad portuaria: había vivido del mar y para el mar; se alimentaba del mar y entregaba al mar el fruto de sus esfuerzos; las calles de Barcelona llevaban los pasos del caminante al mar y por el mar se comunicaba con el resto del mundo. (Mendoza, 2018, p. 28)

Como se subraya repetidas veces en La ciudad de los prodigios, "la época estaba dominada por la fe en las ciencias" (p. 165); de ahí que la ciudad catalana dé tanta importancia a la ciencia y a la industria, que crecen sin interrupciones a lo largo del siglo XIX. Al terminar la Guerra Civil, la vida social se detiene; esta suspensión en el curso de la vida diaria se revela en Nada por medio del ambiente sofocante y nervioso de la ciudad y el silencio, la inercia y la timidez de la calle. Disminuye la velocidad de la vida cotidiana. 
La historia de Andrea se relata a través de oposiciones: espacio cerrado / espacio abierto; casa / universidad-calle; interior / exterior. Cuando Andrea descubre el lenguaje inclusivo y alentador de los compañeros del ambiente universitario, encuentra la posibilidad de poder alejarse de la atmósfera asfixiante de la casa y así de poder respirar:"Me juré que no mezclaría aquellos dos mundos que se empezaban a destacar tan claramente en mi vida: el de mis amistades de estudiante con su fácil cordialidad y el sucio y poco acogedor de mi casa" (Laforet, 2018, p. 113). El agudo contraste entre la lengua amenazante de la casa y la lengua ingeniosa y cariñosa de los compañeros de la universidad determina las preferencias de Andrea. Cuando se enfrentan y chocan las palabras de los habitantes del piso de la calle Aribau - la lengua predicadora, opresiva, intolerante y rígida de Angustias, la lengua violenta y amenazadora de Juan, la lengua manipuladora y sarcástica de Román, la lengua sedante de la abuela, usada con la intención de ocultar la verdad, y la lengua provocativa de Gloria -, Andrea se refugia a veces en la soledad de la calle y a veces en el mundo de sus amigos. Angustias acusa a Andrea de vagabundear por la calle mientras ella no está en casa: “[...] te advierto que sé perfectamente lo que haces cuando yo estoy en mi oficina. Sé que te vas a la calle y vuelves antes de que yo llegue, para que no pueda pillarte. ¿Se puede saber adónde vas?" (p. 109). En respuesta, Andrea le dice que no va a ningún sitio concreto y que le gusta ver las calles, ver la ciudad. La necesidad de huir y salvarse del despotismo de su tía al principio de su estancia, poco a poco va dejando lugar al despertar a un mundo distinto del microcosmos de la casa de la calle de Aribau:"Pero - pensé yo, excitada, después de esta conversación - este período se acaba. Me vi entrar en una vida nueva, en la que dispondría libremente de mis horas [...]" (p. 110). La decisión arbitraria de pasear por las calles sin objetivo alguno en un primer momento cede el paso al conocimiento de que puede emplear su libertad con utilidad. El ámbito acogedor de la universidad salva a Andrea del mundo tóxico de sus parientes y la llena de esperanza: “Cuando volví a reanudar las clases en la universidad me parecía fermentar interiormente de impresiones acumuladas. Por primera vez en mi vida me encontré siendo expansiva y anudando amistades" (pp. 110-111). Andrea se siente indefensa en un mundo hostil donde debe protegerse de la familia. Sin embargo, encuentra apoyo en un lugar donde está rodeada de gente desconocida y busca cobijo en su seno:

La verdad es que me llevaba a ellos un afán indefinible que ahora puedo concretar como un instinto de defensa: sólo aquellos seres de mi misma generación y de mis mismos gustos podían respaldarme y ampararme contra 
el mundo un poco fantasmal de las personas maduras. Y verdaderamente, creo que yo en aquel tiempo necesitaba este apoyo. (Laforet, 2018, p. 111)

\section{Conclusión}

Barcelona forma el telón de fondo en ambos relatos. La historia en Nada empieza en 1939, diez años después de terminar en La ciudad de los prodigios. Se narran, en ambas novelas, las historias de personas jóvenes, que llegan a la gran ciudad con grandes esperanzas de empezar una vida nueva. Las historias de Andrea y de Onofre Bouvila se sitúan en el núcleo de la ciudad, que se narra en dos distintas épocas: la Barcelona de La ciudad de los prodigios pasa por un período de grandes acontecimientos sociales y desarrollo industrial, en una era de fe en las ciencias. El fundamento de la vida es la evolución constante. La Barcelona de Nada pasa por un período crítico de la historia: terminada la Guerra Civil Española, la ciudad está paralizada; la vida social sigue su curso como puede; sin embargo, ya no es posible hablar del crecimiento de diez años atrás. Esta Barcelona y la otra son radicalmente distintas. Sólo diez años después de la inauguración de la segunda Exposición Universal de Barcelona, la ciudad se ha convertido en un fantasma.

Las clases sociales entre 1888 y 1929 forman la lengua de la ciudad: la gente de la construcción, de la posición más alta a la más baja, indica el progreso urbano; el mar es la puerta que se abre al mundo y los obreros portuarios son quienes mantienen relaciones con él; los políticos y burócratas, sensibles al prestigio de la ciudad, tienen ganas de actuar por la ciudad con el fin de situarla entre las grandes ciudades europeas, como se merece; la clase burguesa realiza grandes eventos y requiere un cambio social. Todas las clases que componen la sociedad crean una vida social tumultuosa, agitada y enérgica. De la unión de la energía creadora de estas capas sociales nace la lengua de la ciudad: es una lengua de esperanzas, optimismo y confianza.

Al final de la Guerra Civil, Barcelona tiene una imagen muerta: ya no se habla de evolución ni del prestigio de la ciudad. Toda actividad está detenida; es una cuestión de sobrevivir a la pobreza y el hambre o sólo de seguir viviendo. El Mediterráneo, que comunicaba con el resto del mundo, es ahora un cementerio de buques hundidos en la guerra. La ciudad refleja la falta de vida y la lengua de la ciudad refleja tensión, dolor y violencia. En este ambiente triste, solo los compañeros de Andrea parecen conservar aún el ánimo; no se muestran perturbados por las condiciones del momento. 
En La ciudad de los prodigios la realización del cambio social y la evolución industrial y económica se deben a la ascendente clase burguesa y a las demás clases sociales, que solicitan la transformación. En cambio, la clase burguesa relatada en Nada se dibuja como una decadente clase social que ha perdido sus vínculos con la vida. En La ciudad de los prodigios Onofre Bouvila llega a Barcelona en 1887, a los doce años, como un pobre inmigrante del campo. Con los años se hace rico, ascendiendo a la cumbre del mundo delictivo y financiero y se sitúa entre la sociedad burguesa de Barcelona. Andrea de Nada llega del pueblo a Barcelona en 1939. Es una huérfana de 18 años, que tiene ganas de estudiar en la universidad. En la casa familiar en que empieza a vivir se enfrenta con la sociedad burguesa conservadora de Barcelona y una lengua de violencia y rencor en la vida turbada y sofocante de los miembros de la casa. Barcelona ofrece a Onofre Bouvila ilimitadas opciones para avanzar entre 1887 y 1929; la Barcelona de 1939 mete a Andrea dentro de una trampa y la deja sin aliento. Ambos se despiden de la ciudad al final de su historia personal: Onofre Bouvila deja Barcelona, que lo ha convertido en un hombre rico, pero solitario y enloquecido; Andrea deja atrás la ciudad asfixiante para continuar hacia un futuro incierto.

Sistema de evaluación: Por pares externos.

Conflicto de intereses: La autora declara no tener ningún conflicto de intereses.

Apoyo económico: La autora declara que no ha recibido ningún apoyo económico para este trabajo.

Peer-review: Externally peer-reviewed.

Conflict of Interest: The author has no conflict of interest to declare.

Grant Support: The author declared that this study has received no financial support.

\section{Bibliografía}

Cerezales, A. (1995, enero 13). Nada. ABC literario, p. 22.

Crespo Matellán, S. (1988). Aproximación al concepto de personaje novelesco: los personajes en Nada de Carmen Laforet. Anuario de Estudios Filológicos, 11, 131-148.

Delibes, M. (1990). Pegar la hebra. Barcelona, España: Ediciones Destino.

Garbisu Buesa, M. (2000). El juego realidad - ficción en La ciudad de los prodigios de Eduardo Mendoza. Espéculo: Revista de Estudios Literarios, (16), 16-16.

Giménez Mico, M.J. (2000). Eduardo Mendoza y las novelas españolas de la transición. Madrid, España: Editorial Pliegos.

Hoeg, J. (2007). La ciudad de los prodigios de Eduardo Mendoza frente a una visión latinoamericana de ciencia, cultura y tecnología. Revista Iberoamericana, 73(221), 861-870. 
Kronik, J.W. (1981). Nada y el texto asfixiado: proyección de una estética. Revista lberoamericana, 47(116-117), 195-202.

Laforet, C. (2018). Nada (16 Ed.). Barcelona, España: Editorial Planeta.

Martín Gaite, C. (1993). Desde la ventana: Enfoque femenino de la literatura española. Madrid, España: EspasaCalpe.

Mendoza, E. (2018). La ciudad de los prodigios (6 ${ }^{\mathrm{a}}$ Ed.). Barcelona, España:Editorial Planeta.

Valles Calatrava, J. R. (2017). Papeles y facetas de los personajes en La ciudad de los prodigios de Eduardo Mendoza. Revista Hispánica de Cultura y Literatura, 32(2), 192-203. 